\title{
Evidence for the late formation of hydrous asteroids from young meteoritic carbonates
}

\author{
Wataru Fujiya ${ }^{1}$, Naoji Sugiura ${ }^{1}$, Hideyuki Hotta ${ }^{1}$, Koji Ichimura$^{1} \&$ Yuji Sano ${ }^{2}$
}

The accretion of small bodies in the Solar System is a fundamental process that was followed by planet formation. Chronological information of meteorites can constrain when asteroids formed. Secondary carbonates show extremely old ${ }^{53} \mathrm{Mn}-{ }^{53} \mathrm{Cr}$ radiometric ages, indicating that some hydrous asteroids accreted rapidly. However, previous studies have failed to define accurate $\mathrm{Mn} / \mathrm{Cr}$ ratios; hence, these old ages could be artefacts. Here we develop a new method for accurate $\mathrm{Mn} / \mathrm{Cr}$ determination, and report a reliable age of 4,563.4+0.4/-0.5 million years ago for carbonates in carbonaceous chondrites. We find that these carbonates have identical ages, which are younger than those previously estimated. This result suggests the late onset of aqueous activities in the Solar System. The young carbonate age cannot be explained if the parent asteroid accreted within 3 million years after the birth of the Solar System. Thus, we conclude that hydrous asteroids accreted later than differentiated and metamorphosed asteroids.

\footnotetext{
${ }^{1}$ Department of Earth and Planetary Science, Graduate School of Science, the University of Tokyo, 7-3-1 Hongo, Bunkyo-ku, Tokyo 113-0033, Japan.

2 Atmosphere and Ocean Research Institute, the University of Tokyo, 5-1-5 Kashiwanoha, Kashiwa-shi, Chiba 277-8564, Japan. Correspondence and requests for materials should be addressed to W.F. (email: fujiya@eps.s.u-tokyo.ac.jp).
} 
A $\mathrm{n}$ understanding of the evolution of the asteroid belt can constrain the origin and early history of the Solar System. It is suggested that the accretion time of asteroids determines the degree of metamorphism (and/or melting) they experienced ${ }^{1}$, because a short-lived radionuclide of ${ }^{26} \mathrm{Al}$ (half-life: $0.73 \times 10^{6}$ years) is the dominant heat source of metamorphism, and hence, the abundance of the heat source is a function of accretion time. Several lines of evidence from the dating of meteorites have shown that the parent bodies of differentiated meteorites accreted earlier than chondrites ${ }^{2,3}$. These observations indicate that accretion time is indeed an important controlling factor of asteroidal thermal history, whereas other factors, such as water concentrations in asteroids, could have minor roles. However, the accretion time of hydrous asteroids has been controversial. CM chondrites, which are carbonaceous chondrites named for their type specimen of the Mighei meteorite, experienced aqueous alteration at low temperatures ${ }^{4}$, indicating late accretion. However, the ${ }^{53} \mathrm{Mn}-{ }^{53} \mathrm{Cr}$ ages $\left({ }^{53} \mathrm{Mn}\right.$ decays to ${ }^{53} \mathrm{Cr}$ with a half-life of $3.7 \times 10^{6}$ years) of the carbonates in CM chondrites revealed by secondary ion mass spectrometry (SIMS) are very old (ref. 5 and references therein), with ages comparable to the oldest solids in the Solar System (that is, calcium-aluminium-rich inclusions (CAIs); 4,568.2 million years ago (Myr ago $\left.)^{6}\right)$. Although the ages of the secondary minerals in CI chondrites (named for their type specimen of the Ivuna meteorite) may not be as old (4,567 to 4,554 $\mathrm{Myr}_{\text {ago }}{ }^{7-12}$ ), one must conclude that at least some hydrous asteroids, such as the CM chondrite parent body, accreted very rapidly because the accretion time should be constrained by the oldest alteration product.

It should be noted, however, that the accuracies of $\mathrm{Mn}-\mathrm{Cr}$ ages depend on accurate determinations of ${ }^{55} \mathrm{Mn} /{ }^{52} \mathrm{Cr}$ ratios. Accurate ${ }^{55} \mathrm{Mn} /{ }^{52} \mathrm{Cr}$ measurements of meteoritic carbonates require a carbonate standard with a known chemical composition (that is, ${ }^{55} \mathrm{Mn} /{ }^{52} \mathrm{Cr}$ atomic ratio) because the sensitivities of $\mathrm{Mn}$ and $\mathrm{Cr}$ in SIMS strongly depend on analyte chemical compositions (the socalled 'matrix effect'), and hence, the data obtained for unknown samples should be calibrated using the standard. However, a suitable carbonate standard is not available in natural terrestrial environments, which is why previous studies have used other materials, such as San Carlos olivine, as alternative standards. This use has led to systematic errors on the ${ }^{55} \mathrm{Mn} /{ }^{52} \mathrm{Cr}$ of meteoritic samples and their ages. To overcome this problem, we synthesized a carbonate (calcite: $\mathrm{CaCO}_{3}$ ) standard doped with $\mathrm{Mn}$ and $\mathrm{Cr}$, and we demonstrated that the $\mathrm{Mn} / \mathrm{Cr}$ relative sensitivity of carbonates is significantly different from that of San Carlos olivine ${ }^{13}$, that is, systematic errors of $\sim 2.2 \mathrm{Myr}$ indeed exist in previous studies for carbonate dating. This result is crucial for a high-resolution chronology of the early Solar System.

In the present study, we determined the accurate $\mathrm{Mn}-\mathrm{Cr}$ ages of carbonates in four CM chondrites using the carbonate standard. We found that the CM carbonates have an identical age of $4,563.4_{-0.5}^{+0.4} \mathrm{Myr}$ ago, which is younger than previous estimates. The young carbonate age suggests the late onset of aqueous activities in the Solar System. Based on this result, we conclude that the parent asteroid of CM chondrites accreted at $3.5 \mathrm{Myr}$ after the birth of the Solar System.

\section{Results}

Initial ${ }^{53} \mathrm{Mn} /{ }^{55} \mathrm{Mn}$ ratios and absolute ages of $\mathrm{CM}$ carbonates. We performed $\mathrm{Mn}-\mathrm{Cr}$ isotope measurements of the standard and carbonates in the CM chondrites with different alteration indexes ${ }^{14}$ (calcites in Murchison CM 2.5 and Y791198 CM 2.4 and dolomites in ALH83100 CM 2.1 and Sayama CM 2.1) using a NanoSIMS 50. The $\mathrm{Mn} / \mathrm{Cr}$ relative sensitivity data are presented in Supplementary Figure S1 and Supplementary Table S1. For all samples, the ${ }^{53} \mathrm{Cr}$ excesses correlate well with the ${ }^{55} \mathrm{Mn} /{ }^{52} \mathrm{Cr}$, which indicates the in-situ decay of ${ }^{53} \mathrm{Mn}$ (Fig. 1; Table 1). The analyses were performed for several carbonate grains in each meteorite. Hence, it is likely that the carbonates dispersed in each meteorite formed at the same time within the analytical uncertainties. The initial ${ }^{53} \mathrm{Mn} /{ }^{55} \mathrm{Mn}$ ratios, $\left({ }^{53} \mathrm{Mn} /{ }^{55} \mathrm{Mn}\right)_{0}$, were estimated from the isochron slopes, and the uncertainty in the $\mathrm{Mn} / \mathrm{Cr}$ relative sensitivity was propagated to the errors on $\left({ }^{53} \mathrm{Mn} /{ }^{55} \mathrm{Mn}\right)_{0}$. The $\left({ }^{53} \mathrm{Mn} /{ }^{55} \mathrm{Mn}\right)_{0}$ values were found to be $(2.59 \pm 0.74) \times 10^{-6},(3.31 \pm 0.68) \times 10^{-6},(2.71 \pm 0.40) \times 10^{-6}$ and $(3.28 \pm 0.30) \times 10^{-6}$ for the carbonates in Murchison, Y791198, ALH83100 and Sayama, respectively (errors are $2 \sigma$ ). In calculating the absolute ages of carbonates, the LEW 86010 angrite with a known $\mathrm{Pb}-\mathrm{Pb}$ age ${ }^{15}$ and $\left({ }^{53} \mathrm{Mn} /{ }^{55} \mathrm{Mn}\right)_{0}$ (ref. 16) was referenced as a time anchor. We assume a homogeneous distribution of ${ }^{53} \mathrm{Mn}$ in the early Solar System, which is likely to be correct at least among samples from chondrites, the eucrite parent body, Earth and Mars ${ }^{17}$. The initial ${ }^{53} \mathrm{Mn} /{ }^{55} \mathrm{Mn}$ ratios of the carbonates correspond to absolute ages of 4,562. $6_{-1.9}^{+1.4} \mathrm{Myr}$ ago for Murchison, 4, 563.9 ${ }_{-1.3}^{+1.1} \mathrm{Myr}$ ago for Y791198, 4,562.8 $8_{-1.0}^{+0.8} \mathrm{Myr}$ ago for ALH83100 and 4,563.9 $9_{-0.7}^{+0.6}$ Myr ago for Sayama.

Accuracies of the carbonate ages. It should be stressed that we calculated a Cr isotopic ratio by summing all ${ }^{53} \mathrm{Cr}$ counts, then dividing by the sum of ${ }^{52} \mathrm{Cr}$ counts over the entire measurement, rather than averaging isotopic ratios (Methods). This is an important difference from earlier studies, that is, an isotope ratio has been traditionally calculated by averaging a number of ratios collected over the course of a measurement, which leads to a positive bias especially in the case of low counting rates ${ }^{18}$.

The meteoritic carbonates studied in this study have experienced only low temperatures and it is unlikely that thermally driven volume diffusion has disturbed the $\mathrm{Mn}-\mathrm{Cr}$ system. Also, other mechanisms of redistribution of the parent and daughter isotopes, such as grain boundary diffusion, can be ruled out because the cathodeluminescence observations of the carbonates show well-preserved zoning of trace elements including Mn. Therefore, we are sure that these ages are indigenous and there are no possibilities of age biases caused by the disturbance of the Mn-Cr system.

In summary, we successfully determined the carbonate ages of the CM chondrites, which are free from the potential biases resulting from the matrix-mismatched standard, the calculation of isotopic ratios and/or the disturbance of the Mn-Cr system.

\section{Discussion}

It is worth noting that the carbonate ages are younger than those reported previously for the same meteorites. These ages are identical within the errors, irrespective of the degrees of aqueous alteration (Fig. 2). Therefore, we can define a formation age of $4,563.4_{-0.5}^{+0.4}$ Myr ago (that is, $4.8 \mathrm{Myr}$ after CAI formation) for carbonates in $\mathrm{CM}$ chondrites using the weighted average. Our data indicate a later accretion of the CM chondrite parent asteroid, and therefore, later onsets of aqueous alteration in the Solar System than previously inferred from the oldest carbonates in the CM chondrites. The problem of the very early formation of carbonates contemporaneous with CAIs is solved using the proper $\mathrm{Mn} / \mathrm{Cr}$ relative sensitivity. It is also suggested that the carbonates in the CM chondrites precipitated in a relatively short time. This suggestion is contrary to earlier studies suggesting a rough correlation between alteration indexes and carbonate ages of CM chondrites ${ }^{5}$.

Here we consider the accretion time of the CM chondrite parent body. Our new carbonate ages determine the younger side of the accretion time ( $\sim .8 \mathrm{Myr}$ after CAI formation). The older side could be constrained by the ${ }^{53} \mathrm{Mn}-{ }^{53} \mathrm{Cr}$ or ${ }^{26} \mathrm{Al}-{ }^{26} \mathrm{Mg}$ ages of chondrules. Unfortunately, chondrules in CM chondrites have not been dated yet, and their dating may be complicated by extensive aqueous alteration. Therefore, we rely on the $\mathrm{Al}-\mathrm{Mg}$ ages of chondrules in $\mathrm{CO}$ chondrites (named for their type specimen of the Ornans meteorite), because they are related to CM chondrites in chemical and oxygen isotopic compositions ${ }^{19,20}$. Previous studies suggested that the 

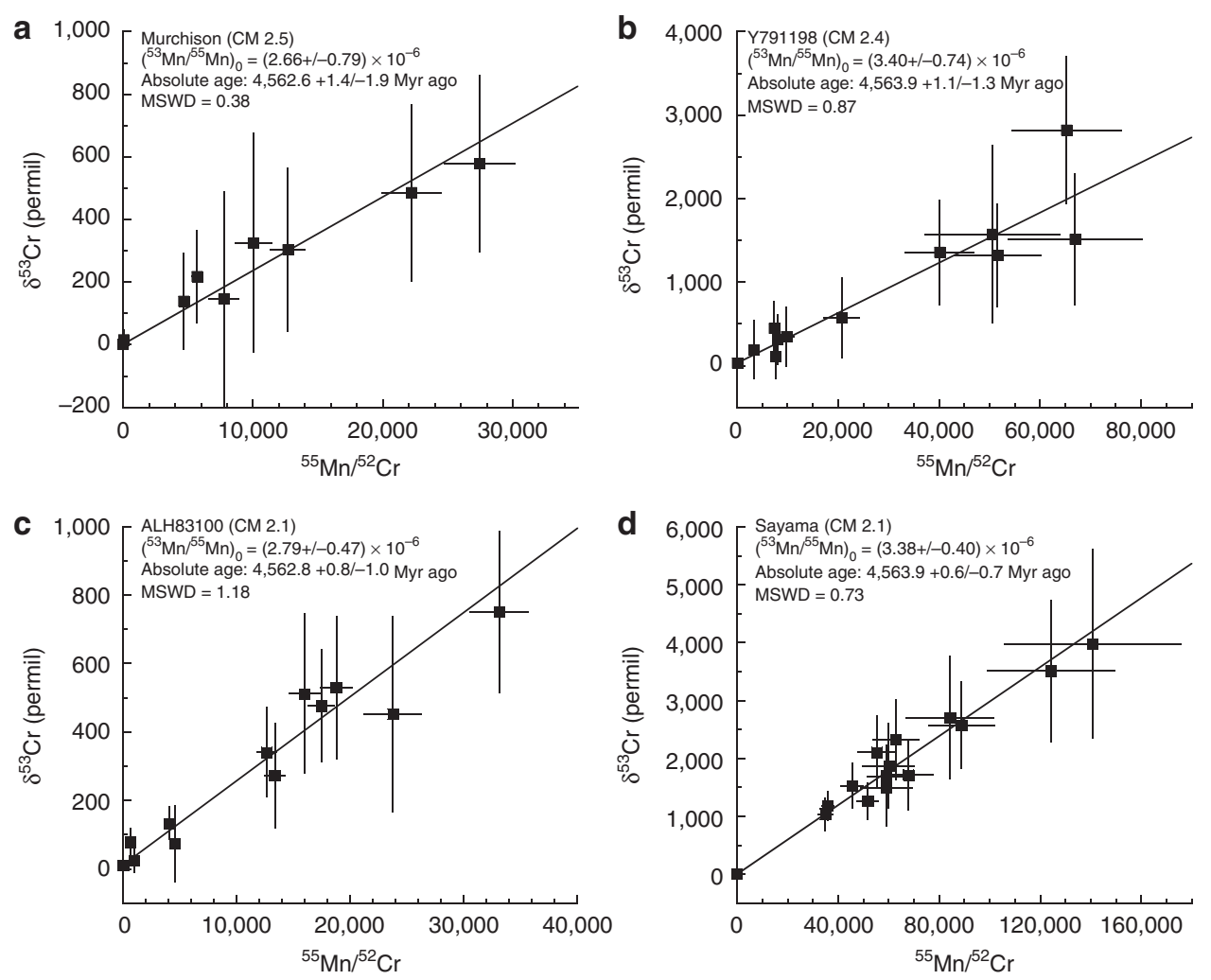

Figure 1 | Mn-Cr isochron diagrams for carbonates in four CM chondrites. (a) Calcite in the Murchison CM 2.5 chondrite. (b) Calcite in the Y791198 CM 2.4 chondrite. (c) Dolomite in the ALH83100 CM 2.1 chondrite. (d) Dolomite in the Sayama CM 2.1 chondrite. The vertical axis shows ${ }^{53} \mathrm{Cr} /{ }^{52} \mathrm{Cr}$ described as the permil deviation $\left(\delta^{53} \mathrm{Cr}\right.$ ) from the value of the synthetic calcite standard. Error bars $( \pm 2 \sigma)$ on both ${ }^{53} \mathrm{Cr} /{ }^{52} \mathrm{Cr}$ and ${ }^{55} \mathrm{Mn} /{ }^{52} \mathrm{Cr}$ represent the external reproducibility or the internal precision, whichever is larger. MSWD, mean square weighted deviation.

forming events of $\mathrm{CO}$ chondrules took place 1.7 to 3.2 Myr after CAI formation $^{21,22}$. Thus, the accretion time of the CM chondrite parent body would be 3.2 to $4.8 \mathrm{Myr}$ after the birth of the Solar System.

On the basis of the chronological information discussed above, we simulate the thermal history of the CM chondrite parent body and estimate the accretion time. We consider the static water model ${ }^{20,23}$ here, although the fluid flow model has been investigated in some previous works ${ }^{24-27}$. The thermal history is modelled using a onedimensional heat conduction equation in radial form. See Supplementary Methods for details. We assume that an asteroid of $60 \mathrm{~km}$ in diameter accreted instantaneously at $3.5 \mathrm{Myr}$ (case A) or 3.0 Myr (case B) after CAI formation, although the results are essentially similar for different asteroid sizes, if the asteroid is larger than $60 \mathrm{~km}$ in diameter (Supplementary Fig. S2). The parent body consists of a homogeneous mixture of rock, void space and water ice. The heat source is the decay energy of ${ }^{26} \mathrm{Al}$, and the reaction heat of hydration is also included. The parameters and variables used in the model are presented in Supplementary Table S2 and Supplementary Methods. According to the oxygen isotopic compositions ${ }^{23}$ and a simulation of chemistry during aqueous alteration ${ }^{28}$, the calcite in Murchison is likely to have precipitated at $<25^{\circ} \mathrm{C}$ in the earliest stage of aqueous alteration (when less than a few percent of rock reacted with water). The clumped-isotope thermometry also suggests that the calcite in Murchison formed at a low temperature $\left(20-33^{\circ} \mathrm{C}\right)^{29}$. On the other hand, the dolomite in Sayama seems to have formed at a higher temperature $\left(>120^{\circ} \mathrm{C}\right)$, as inferred from the small isotopic fractionation of oxygen between the dolomite and the matrix ${ }^{30}$.

In the model set-up described above, the calculated thermal history of case A well reproduces the temperatures of carbonate formation at 4,563.4 ${ }_{-0.5}^{+0.4} \mathrm{Myr}$ ago (Fig. 3a). In the intermediate region of the asteroid, the peak temperature is less than $\sim 50^{\circ} \mathrm{C}$, and the progress of aqueous alteration is mild. In the inner part, on the other hand, the peak temperature is $\sim 150^{\circ} \mathrm{C}$, and alteration occurs rapidly. While less altered $\mathrm{CM}$ chondrites, such as Murchison, could be derived from the outer part of the asteroid, more altered ones, such as Sayama, come from the inner part. In contrast, case B gives a rapid increase in temperature caused by more abundant ${ }^{26} \mathrm{Al}$, even if the hydration heat is not considered, and as a consequence, the carbonates are likely to have precipitated at $\sim 4,564.5 \mathrm{Myr}$ ago (Fig. 3b). Other heat sources, such as impact heating, inductive heating or decay energies of other radioactive nuclides, if any, would assist the ${ }^{26} \mathrm{Al}$ heating of the parent body, resulting in a more rapid temperature increase. Therefore, such early accretion as case B is ruled out considering our high-precision $\mathrm{Mn}-\mathrm{Cr}$ data. Although parameters such as water fraction and the size of the asteroid are not well constrained, it is important to stress that there is no parameter space where carbonates could form at $4.8 \mathrm{Myr}$ after CAI formation, if the parent body accreted within 3.0 Myr after CAI formation, because the timing at which the aqueous alteration began was determined predominantly by the accretion time of the asteroid.

An accretion time of $>3 \mathrm{Myr}$ after CAI formation is later than the formation of chondrules in the least metamorphosed chondrites (typically $\sim 2 \mathrm{Myr}$ after CAI formation ${ }^{3}$ ). On the other hand, the W isotopic compositions of iron meteorites suggest their formation within $1.5 \mathrm{Myr}$ after CAI formation ${ }^{2}$. If the carbonate ages of CI chondrites reported so far also have systematic errors, like those of the CM chondrites, they would become comparable with or younger than the carbonate ages of the CM chondrites ${ }^{8,10-12}$. In any case, the early formation of hydrous asteroids suggested by old carbonates in CM chondrites is no longer well founded, and we conclude that hydrous asteroids accreted later than differentiated and metamorphosed asteroids. This conclusion is consistent with the composi- 
Table 1 | Mn-Cr isotope data of carbonates in four CM chondrites.

\begin{tabular}{|c|c|c|c|c|c|c|c|c|}
\hline Grain & ${ }^{55} \mathrm{Mn}$ (counts) & ${ }^{52} \mathrm{Cr}$ (counts) & ${ }^{53} \mathrm{Cr}$ (counts) & ${ }^{52} \mathrm{Cr}(\mathrm{cps} / \mathrm{nA})$ & ${ }^{55} \mathrm{Mn} /{ }^{52} \mathrm{Cr}$ & Error & $\delta^{53} \mathrm{Cr}(\%)$ & Error \\
\hline \multicolumn{9}{|l|}{ Murchison } \\
\hline Calcite_A & $5.45 . E+06$ & 386 & 158 & 0.835 & 22,228 & 2,263 & 486 & 281 \\
\hline Calcite_A & $4.20 . E+06$ & 1,094 & 368 & 2.50 & 5,684 & 374 & 218 & 147 \\
\hline Calcite_A & 7.71.E + 05 & 20,237 & 5,669 & 112 & 54 & 4 & 16 & 31 \\
\hline Calcite_B & 1.37.E+ 06 & 217 & 79 & 1.14 & 10,026 & 1,361 & 326 & 348 \\
\hline Calcite_B & 3.29.E+ 06 & 379 & 136 & 0.783 & 12,686 & 1,303 & 304 & 260 \\
\hline Calcite_E & $9.12 . E+05$ & 189 & 60 & 0.242 & 7,747 & 1,128 & 148 & 341 \\
\hline \multicolumn{9}{|l|}{ Y791198 } \\
\hline Calcite_A & 2.12.E + 06 & 143 & 62 & 0.478 & 20,750 & 3,465 & 574 & 478 \\
\hline Calcite_A & $5.44 . E+06$ & 147 & 94 & 0.492 & 51,556 & 8,491 & 1,319 & 612 \\
\hline Calcite_B & 1.78.E+ 06 & 300 & 109 & 2.68 & 8,057 & 931 & 317 & 295 \\
\hline Calcite_E & 4.65.E+ 05 & 192 & 63 & 0.822 & 3,369 & 486 & 192 & 346 \\
\hline Calcite_F & $4.79 . E+06$ & 101 & 70 & 0.338 & 66,967 & 13,295 & 1,512 & 780 \\
\hline Calcite_F & $6.76 . E+06$ & 148 & 156 & 0.495 & 65,268 & 10,712 & 2,819 & 875 \\
\hline Calcite_G & 1.56.E + 06 & 296 & 118 & 1.10 & 7,389 & 859 & 449 & 315 \\
\hline \multicolumn{9}{|l|}{ ALH83100 } \\
\hline Dolomite_A & $9.23 . E+06$ & 1,064 & 374 & 5.85 & 13,372 & 879 & 273 & 153 \\
\hline Dolomite_B & 6.13.E + 06 & 578 & 241 & 4.73 & 15,987 & 1,331 & 512 & 232 \\
\hline Dolomite_C & $2.32 . E+07$ & 9,698 & 3,033 & 40.7 & 4,074 & 268 & 134 & 47 \\
\hline Dolomite_C & 1.19.E + 07 & 1,151 & 469 & 3.84 & 17,468 & 1,148 & 477 & 162 \\
\hline Dolomite_C & $5.93 . E+06$ & $1,223,345$ & 341,521 & 4,078 & 25 & 2 & 12 & 4 \\
\hline Dolomite_D & $5.42 . E+06$ & 12,393 & 3,688 & 88.5 & 672 & 44 & 79 & 40 \\
\hline Dolomite_E & $8.93 . E+06$ & 15,632 & 4,417 & 52.1 & 963 & 63 & 25 & 35 \\
\hline Dolomite_A & $2.02 . E+07$ & 562 & 351 & 1.87 & 51,629 & 4,354 & 1,266 & 308 \\
\hline Dolomite_A & $9.03 . E+06$ & 99 & 123 & 0.865 & 124,314 & 25,030 & 3,513 & 1,221 \\
\hline Dolomite_B & $6.71 . E+06$ & 65 & 89 & 0.578 & 140,802 & 35,012 & 3,978 & 1,628 \\
\hline Dolomite_B & $6.02 . E+06$ & 97 & 99 & 0.896 & 84,327 & 17,148 & 2,709 & 1,061 \\
\hline Dolomite_C & 1.46.E+ 07 & 604 & 339 & 2.01 & 34,879 & 2,837 & 1,037 & 276 \\
\hline Dolomite_C & 1.34.E+ 07 & 423 & 295 & 1.50 & 45,455 & 4,422 & 1,531 & 384 \\
\hline Dolomite_D & $9.32 . E+06$ & 190 & 142 & 1.14 & 67,826 & 9,840 & 1,715 & 602 \\
\hline Dolomite_D & $6.12 . E+06$ & 141 & 97 & 1.23 & 59,134 & 9,972 & 1,494 & 659 \\
\hline Dolomite_D & $9.89 . E+06$ & 235 & 174 & 1.16 & 59,160 & 7,724 & 1,693 & 539 \\
\hline Dolomite_D & $6.33 . E+06$ & $2,578,365$ & 713,592 & 18,157 & 4 & 0.2 & 5 & 7 \\
\hline Dolomite_E & 2.19.E+ 07 & 881 & 530 & 2.94 & 35,729 & 2,407 & 1,183 & 240 \\
\hline Dolomite_E & $8.60 . E+06$ & 221 & 189 & 0.830 & 55,344 & 7,448 & 2,109 & 616 \\
\hline Dolomite_F & $6.19 . E+06$ & 141 & 111 & 1.12 & 60,012 & 10,125 & 1,875 & 730 \\
\hline Dolomite_F & $8.84 . E+06$ & 197 & 180 & 0.973 & 62,850 & 8,964 & 2,324 & 686 \\
\hline
\end{tabular}

tional structure of the asteroid belt, which shows that asteroids with spectra indicative of high-temperature silicate minerals are concentrated between 1.8 and $3 \mathrm{AU}$, whereas dark C-rich types seem to be located farther away from the Sun ${ }^{31}$.

\section{Methods}

NanoSIMS measurement condition. We performed the $\mathrm{Mn}-\mathrm{Cr}$ isotope measurements using a NanoSIMS 50 installed at the Atmosphere and Ocean Research Institute at the University of Tokyo. Both the meteorites and the synthetic calcite standard were embedded in epoxy and polished in the same way. A focused $\mathrm{O}^{-}$ primary ion beam of $1 \mathrm{nA}$ was accelerated to $16 \mathrm{keV}$ and irradiated on the surfaces of the samples. Before the measurements, an intense primary beam of $\sim 3 \mathrm{nA}$ was rastered over $20 \times 20$ to $50 \times 50 \mu \mathrm{m}^{2}$ on the meteoritic carbonates to remove surface contaminations and to obtain secondary ion images of carbonates to choose measurement spots. Secondary ions were extracted from the sample surfaces by an accelerating voltage of $8 \mathrm{kV}$, and ${ }^{43} \mathrm{Ca}^{+},{ }^{52} \mathrm{Cr}^{+},{ }^{53} \mathrm{Cr}^{+}$and ${ }^{55} \mathrm{Mn}^{+}$ions were detected in a combined peak-jumping/multi-detection mode. The magnet was cycled through two field settings and the waiting times were 2 seconds each. In the first setting, ${ }^{43} \mathrm{Ca}^{+},{ }^{52} \mathrm{Cr}^{+}$and ${ }^{55} \mathrm{Mn}^{+}$were simultaneously detected with three secondary electron multipliers (SEMs). The measurement time was 2 seconds. 


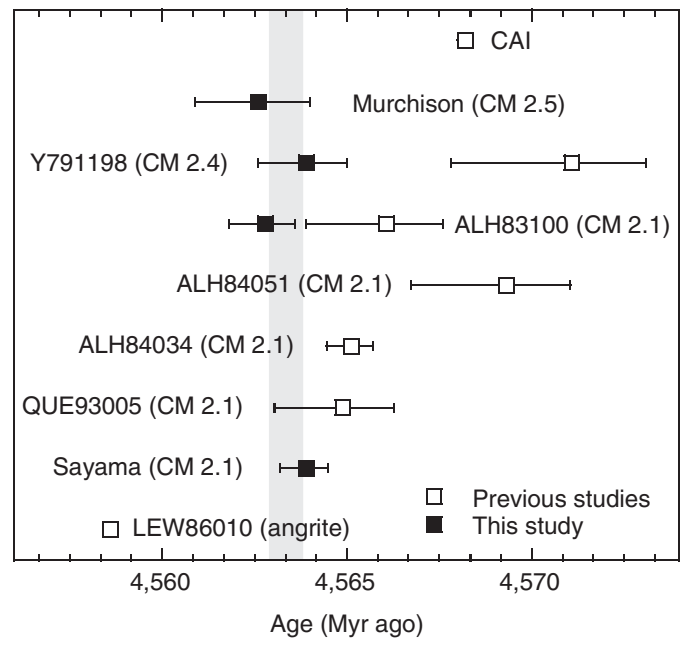

Figure $\mathbf{2}$ | Summary and comparison of $\mathbf{M n}-\mathbf{C r}$ ages of carbonates.

The filled symbols represent $\mathrm{Mn}-\mathrm{Cr}$ ages in this study using the calcite standard, and the open symbols represent previously reported data (ref. 5 and references therein). Also shown are the $\mathrm{Pb}-\mathrm{Pb}$ age of a type- $\mathrm{B} \mathrm{CAl}$ from the NWA2364 CV3 chondrite ${ }^{6}$ (named for their type specimen of the Vigarano meteorite) and the $\mathrm{Pb}-\mathrm{Pb}$ age of the LEW86010 angrite ${ }^{15}$ used as a time anchor. The carbonates in the four $\mathrm{CM}$ chondrites analysed here show an identical formation age $\left(4,563.4_{-0.5}^{+0.4}\right.$; shown by the vertical grey band). Error bars $( \pm 2 \sigma)$ are based on the uncertainties of the Mn/Cr RSF and the isochron slopes (see Methods for details).

Subsequently, ${ }^{53} \mathrm{Cr}^{+}$was detected with the same SEM as that for ${ }^{52} \mathrm{Cr}^{+}$. The measurement time was 5 seconds. The measurements consisted of 150 cycles of the two magnetic field settings. The difference between sensitivities of two SEMs for ${ }^{52} \mathrm{Cr}^{+}$and ${ }^{55} \mathrm{Mn}^{+}$was corrected when evaluating the $\mathrm{Mn} / \mathrm{Cr}$ relative sensitivity of carbonates, although this difference was cancelled when we calculated the ${ }^{55} \mathrm{Mn} /{ }^{52} \mathrm{Cr}$ of the meteoritic samples and normalized it to the standard value. The dynamic background of the SEM for ${ }^{52,53} \mathrm{Cr}^{+}$was measured by applying a $-10 \mathrm{~V}$ offset relative to the peak centre on the deflection plates in front of the SEMs. The background ranged from 0.01 to $0.02 \mathrm{cps}$.

$\mathrm{Mn} / \mathrm{Cr}$ relative sensitivity of carbonates. We synthesised a calcite standard doped with $\mathrm{Mn}$ and $\mathrm{Cr}$ to evaluate the relative sensitivity factor (RSF; defined as $\left.\left({ }^{55} \mathrm{Mn}^{+} /{ }^{52} \mathrm{Cr}^{+}\right)_{\text {ion }} /\left({ }^{55} \mathrm{Mn} /{ }^{52} \mathrm{Cr}\right)_{\text {atomic }}\right)$ of carbonates. See ref. 13 for details of the production. The synthetic calcite has concentration gradients of $\mathrm{Mn}$ and $\mathrm{Cr}$ in a single grain. The concentrations decrease from the centre to periphery of a grain due to the fractional crystallization of $\mathrm{Mn}$ and $\mathrm{Cr}$. Therefore, we analysed the grains for small regions within $100 \times 100 \mu \mathrm{m}^{2}$ of the grain centre. In these limited areas, the heterogeneities of $\mathrm{Mn}$ and $\mathrm{Cr}$ are up to $20 \%$.

The ${ }^{55} \mathrm{Mn} /{ }^{52} \mathrm{Cr}$ atomic ratios were determined with an electron probe micro analyser (EPMA) around measurement spots with a NanoSIMS. In the EPMA analyses, the $\mathrm{Mg}, \mathrm{Ca}, \mathrm{Cr}, \mathrm{Mn}$ and $\mathrm{Fe}$ concentrations were determined with a JEOL JXA-8900L. A sample current of $3 \mathrm{nA}$ was accelerated to $15 \mathrm{keV}$ and rastered over $\sim 10 \times 10 \mu \mathrm{m}^{2}$ on the sample surface to avoid damage by electron bombardment. The measurement times of the $\mathrm{Mg}, \mathrm{Ca}, \mathrm{Cr}, \mathrm{Mn}$ and Fe concentrations and the background were 10 seconds and 5 seconds, respectively.

In the NanoSIMS analyses, we found that the ${ }^{43} \mathrm{Ca}^{+},{ }^{52,53} \mathrm{Cr}^{+}$and ${ }^{55} \mathrm{Mn}^{+}$ intensities and the ${ }^{55} \mathrm{Mn}^{+} /{ }^{52} \mathrm{Cr}^{+}$decrease with time for the standard and meteoritic carbonates during a single measurement (Supplementary Fig. S1). This effect is too large to be attributable to the heterogeneities of $\mathrm{Mn}$ and $\mathrm{Cr}$ in a grain, but rather is due to the charge-up of the calcite. Hence, we used the time-dependent RSF' (hereafter described as 'RSF $(t)$ ') to calibrate the ${ }^{55} \mathrm{Mn} /{ }^{52} \mathrm{Cr}$ atomic ratios of the meteoritic samples. The RSF $(t)$ was defined for each measurement cycle (the measurement consisted of 150 cycles of two magnetic field settings). We measured the RSF approximately ten times in each measurement session (the overall measurement consists of three sessions, see Supplementary Fig. S1 and Supplementary Table S1), and the average of approximately ten RSF values at a given time (measurement cycle) was used as the $\operatorname{RSF}(t)$ at the time. Then, we calculated the ${ }^{55} \mathrm{Mn}^{+}{ }^{+}$onvert' of the meteoritic carbonates at a given time as ${ }^{55} \mathrm{Mn}^{+}$convert. $={ }^{55} \mathrm{Mn}^{+} / \mathrm{RSF}(t)$. Finally, we determined the mean ${ }^{55} \mathrm{Mn} /{ }^{52} \mathrm{Cr}$ atomic ratios of the meteoritic carbonates (Table 1 ), as ${ }^{55} \mathrm{Mn} /{ }^{52} \mathrm{Cr}=\Sigma\left({ }^{55} \mathrm{Mn}^{+}\right.$convert. $) / \Sigma\left({ }^{52} \mathrm{Cr}^{+}\right)$. We did not use the average of the ${ }^{55} \mathrm{Mn}^{+}$convert. ${ }^{52} \mathrm{Cr}^{+}$values in the 150 cycles as the mean ${ }^{55} \mathrm{Mn} /{ }^{52} \mathrm{Cr}$ atomic ratio, because the intensity of ${ }^{52} \mathrm{Cr}^{+}$was usually quite low, and ${ }^{55} \mathrm{Mn}^{+}{ }_{\text {convert }}{ }^{152} \mathrm{Cr}^{+}$was often infinite (no ${ }^{52} \mathrm{Cr}^{+}$ion was detected in the
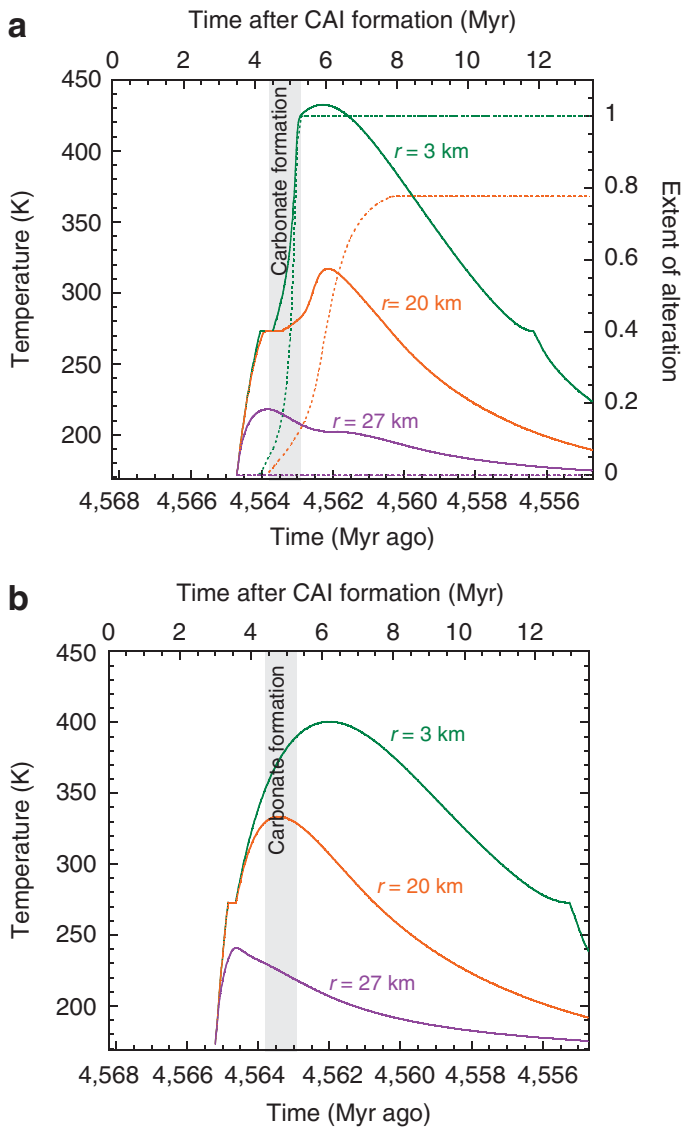

Figure 3 | Thermal history of CM chondrite parent body without fluid flow. Temperature (solid lines) and the extent of alteration (dotted lines) are given at three depths ( $r$ : distance from the centre) in the asteroid with a radius of $30 \mathrm{~km}$. The vertical grey band shows the formation age of carbonates $\left(4,563.4_{-0.5}^{+0.4}\right)$. (a) Accretion at 3.5 Myr after CAl formation (case A). The extent of alteration is defined by (1-olivine res. $_{\text {/olivine }}$ ini.),

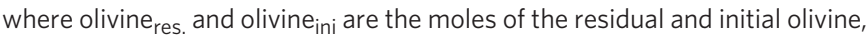
respectively. (b) Accretion at 3.0 Myr after CAI formation (case B). Note that the hydration reaction is not included in case $B$.

cycle). The internal errors on ${ }^{55} \mathrm{Mn} /{ }^{52} \mathrm{Cr}$ were calculated as

$\sigma_{55} \mathrm{Mn} /{ }^{52} \mathrm{Cr}={ }^{55} \mathrm{Mn} /{ }^{52} \mathrm{Cr} \times \sqrt{1 /\left(\Sigma^{55} \mathrm{Mn}^{+}\right)+1 /\left(\Sigma^{52} \mathrm{Cr}^{+}\right)}$.

Note that $\Sigma\left({ }^{55} \mathrm{Mn}^{+}\right)$instead of $\Sigma\left({ }^{55} \mathrm{Mn}^{+}\right.$convert. $)$was used in calculating the internal error.

The uncertainty in the RSF ( $\left.\sigma_{\mathrm{RSF}}\right)$ is difficult to estimate. In the three measurement sessions, the average $\operatorname{RSF}(t)$ values are $0.636,0.675$ and 0.690 , respectively (Supplementary Table S1). These values vary within $8.1 \%$, although the error in each session is less than $2.4 \%$. This variation seems to be caused by the behaviours of the ${ }^{55} \mathrm{Mn}^{+} / 52 \mathrm{Cr}^{+}$changes, that is, degrees of charge-up. The degrees of charge-up are likely to be closely related to crater depth produced by primary ion bombardment, which is controlled by the intensity of the primary ion beam in each measurement session. In each measurement session, we found that the change was reproducible, as shown in Supplementary Figure S1, because we kept the measurement conditions exactly the same including the primary ion beam intensity, which is why the error of the RSF in each session is smaller than the variation among the three sessions. Thus, we are quite sure that the ${ }^{55} \mathrm{Mn} /{ }^{52} \mathrm{Cr}$ of the meteoritic carbonates is properly corrected for the RSF in each measurement session. In this study, we conservatively adopted a $\sigma_{\mathrm{RSF}}$ of $8.1 \%$. We consider that this value can fully describe the uncertainty in the estimated ${ }^{55} \mathrm{Mn} /{ }^{52} \mathrm{Cr}$ ratios, or rather, might be overestimated. This uncertainty was propagated to the final errors on the initial ${ }^{53} \mathrm{Mn} /{ }^{55} \mathrm{Mn}$ ratios, $\left({ }^{53} \mathrm{Mn} /{ }^{55} \mathrm{Mn}\right)$, which were calculated as

$$
\sigma_{\left({ }^{53} \mathrm{Mn} /{ }^{55}\right)_{0}}=\left({ }^{53} \mathrm{Mn} /{ }^{55} \mathrm{Mn}\right)_{0} \times \sqrt{\sigma_{\text {slope }}^{2}+\sigma_{\mathrm{RSF}}^{2}},
$$

where $\sigma_{\text {slope }}$ is the $95 \%$ confident interval of the isochron slope based on $\sigma_{55} \mathrm{Mn} /{ }^{52} \mathrm{Cr}$ and $\sigma_{53} \mathrm{Cr} /{ }^{52} \mathrm{Cr}$ using the York fit program 'Isoplot 3.41' (ref. 32). $\sigma_{53} \mathrm{Cr} /{ }^{52} \mathrm{Cr}$ will be defined in the next subsection. 
Chromium isotope measurements. In contrast to the RSF, the Cr isotopic composition is stable for the synthetic calcite standard during a single measurement The mean values of ${ }^{53} \mathrm{Cr} /{ }^{52} \mathrm{Cr}$ are 0.1103 (1), 0.1102 (3) and 0.1099 (2) in the three measurement sessions, respectively, where the numbers in parentheses represent the uncertainties of the last digits (Supplementary Table S1). We calculated the ${ }^{53} \mathrm{Cr} /{ }^{52} \mathrm{Cr}$ of the meteoritic carbonates as ${ }^{53} \mathrm{Cr} /{ }^{52} \mathrm{Cr}=\Sigma\left({ }^{53} \mathrm{Cr}^{+}\right) / \Sigma\left({ }^{52} \mathrm{Cr}^{+}\right)$. We did not use the average of the ${ }^{53} \mathrm{Cr}^{+} / 52 \mathrm{Cr}^{+}$values in the 150 cycles as the mean ${ }^{53} \mathrm{Cr} /{ }^{52} \mathrm{Cr}$ ratio for the same reason as that for ${ }^{55} \mathrm{Mn} /{ }^{52} \mathrm{Cr}$. The ${ }^{53} \mathrm{Cr} /{ }^{52} \mathrm{Cr}$ of the meteoritic carbonates is described as the permil deviation $\left(\delta^{53} \mathrm{Cr}\right)$ from the standard value (Table 1). The internal errors on ${ }^{53} \mathrm{Cr} /{ }^{52} \mathrm{Cr}\left(\sigma_{53} \mathrm{Cr} /{ }^{52} \mathrm{Cr}\right)$ were calculated as

$\sigma_{53} \mathrm{Cr} /{ }^{52} \mathrm{Cr}={ }^{53} \mathrm{Cr} /{ }^{52} \mathrm{Cr} \times \sqrt{1 /\left(\Sigma^{52} \mathrm{Cr}^{+}\right)+1 /\left(\Sigma^{53} \mathrm{Cr}^{+}\right)}$.

\section{References}

1. Grimm, R. E. \& McSween, H. Y. Jr. Heliocentric zoning of the asteroid belt by aluminum-26 heating. Science 259, 653-655 (1993).

2. Qin, L. et al. Rapid accretion and differentiation of iron meteorite parent bodies inferred from ${ }^{182} \mathrm{Hf}_{-}{ }^{182} \mathrm{~W}$ chronometry and thermal modeling. Earth Planet. Sci. Lett. 273, 94-104 (2008).

3. Krot, A. N. et al. Origin and chronology of chondritic components: a review. Geochim. Cosmochim. Acta 73, 4963-4997 (2009).

4. Brearley, A. J. in Meteorites and the Early Solar System II (eds Lauretta, D. S. \& McSween, H. Y. Jr) 587-624 (Univ. Arizona Press, 2006).

5. de Leuw, S., Rubin, A. E., Schmitt, A. K. \& Wasson, J. T. ${ }^{53} \mathrm{Mn}-{ }^{53} \mathrm{Cr}$ systematics of carbonates in CM chondrites: implications for the timing and duration of aqueous alteration. Geochim. Cosmochim. Acta 73, 7433-7442 (2009).

6. Bouvier, A. \& Wadhwa, M. The age of the Solar System redefined by the oldest $\mathrm{Pb}-\mathrm{Pb}$ age of a meteoritic inclusion. Nat. Geosci. 3, 637-641 (2010).

7. Macdougall, J. D., Lugmair, G. W. \& Kerridge, J. F. Early Solar System aqueous activity: Sr isotope evidence from the Orgueil CI meteorite. Nature 307, 249-251 (1984).

8. Endress, M., Zinner, E. \& Bischoff, A. Early aqueous activity on primitive meteorite parent bodies. Nature 379, 701-703 (1996)

9. Hohenberg, C. M., Pravdivtseva, O. \& Meshik, A. Reexamination of anomalous I-Xe ages: orgueil and Murchison magnetites and Allegan feldspar. Geochim. Cosmochim. Acta 64, 4257-4262 (2000)

10. Hoppe, P., Macdougall, J. D. \& Lugmair, G. W. High spatial resolution ion microprobe measurements refine chronology of carbonate formation in Orgueil. Meteorit. Planet. Sci. 42, 1309-1320 (2007).

11. Petitat, M. et al. Duration and sequence of carbonate crystallization on the Orgueil protolith: ${ }^{53} \mathrm{Mn}-{ }^{53} \mathrm{Cr}$ systematics of their evolution in $\mathrm{O}$ and $\mathrm{C}$ isotopic composition. Lunar Planet. Sci. Conf. XL A1657 (2009).

12. Petitat, M. et al. ${ }^{53} \mathrm{Mn}-{ }^{53} \mathrm{Cr}$ ages of Kaidun carbonates. Meteorit. Planet. Sci. 46, 275-283 (2011).

13. Sugiura, N., Ichimura, K., Fujiya, W. \& Takahata, N. Mn/Cr relative sensitivity factors for synthetic calcium carbonate measured with a NanoSIMS ion microprobe. Geochem. J. 44, e11-e16 (2010).

14. Rubin, A. E., Trigo-Rodríguez, J. M., Huber, H. \& Wasson, J. T. Progressive aqueous alteration of CM carbonaceous chondrites. Geochim. Cosmochim. Acta 71, 2361-2382 (2007).

15. Amelin, $\mathrm{Y}$. U-Pb ages of angrites. Geochim. Cosmochim. Acta 72, 221-232 (2008).

16. Lugmair, G. W. \& Shukolyukov, A. Early solar system timescales according to ${ }^{53} \mathrm{Mn}-{ }^{53} \mathrm{Cr}$ systematics. Geochim. Cosmochim. Acta 62, 2863-2886 (1998).

17. Trinquier, A. et al. ${ }^{53} \mathrm{Mn}-{ }^{53} \mathrm{Cr}$ systematics of the early Solar System revisited. Geochim. Cosmochim. Acta 72, 5146-5163 (2008).

18. Ogliore, R. C., Huss, G. R. \& Nagashima, K. in Nuclear Instruments and Methods in Physics Research B 269, 1910-1918 (2011).

19. Kallemeyn, G. W. \& Wasson, J. T. The compositional classification of chondrites ${ }^{-}$T The carbonaceous chondrite groups. Geochim. Cosmochim. Acta 45, 1217-1230 (1981).
20. Clayton, R. N. \& Mayeda, T. K. Oxygen isotope studies of carbonaceous chondrites. Geochim. Cosmochim. Acta 63, 2089-2104 (1999).

21. Kunihiro, T., Rubin, A. E., McKeegan, K. D. \& Wasson, J. T. Initial ${ }^{26} \mathrm{Al} /{ }^{27} \mathrm{Al}$ ratio in carbonaceous-chondrite chondrules: too little ${ }^{26} \mathrm{Al}$ to melt asteroids. Geochim. Cosmochim. Acta 68, 2947-2957 (2004).

22. Kurahashi, E., Kita, N. T., Nagahara, H. \& Morishita, $\mathrm{Y}^{26} \mathrm{Al}-{ }^{26} \mathrm{Mg}$ systematics of chondrules in a primitive $\mathrm{CO}$ chondrite. Geochim. Cosmochim. Acta 72, 3865-3882 (2008).

23. Clayton, R. N. \& Mayeda, T. K. The oxygen isotope record in Murchison and other carbonaceous chondrites. Earth Planet. Sci. Lett. 67, 151-161 (1984).

24. Grimm, R. E. \& McSween, H. Y. Jr. Water and the thermal evolution of carbonaceous chondrite parent bodies. Icarus 82, 244-280 (1989).

25. Cohen, B. A. \& Coker, R. F. Modeling of Liquid water on CM meteorite parent bodies and implications for amino acid racemization. Icarus 145, 369-381 (2000).

26. Young, E. D., Ash, R. D., England, P. \& Rumble, D. Fluid flow in chondritic parent bodies: deciphering the compositions of planetesimals. Science 286, 1331-1335 (1999).

27. Palguta, J., Schubert, G. \& Travis, B. Fluid flow and chemical alteration in carbonaceous chondrite parent bodies. Earth Planet. Sci. Lett. 296, 235-243 (2010).

28. Zolensky, M. E., Bourcier, W. L. \& Gooding, J. L. Aqueous alteration on the hydrous asteroids: results of EQ3/6 computer simulations. Icarus 78, 411-425 (1989).

29. Guo, W. \& Eiler, J. M. Temperatures of aqueous alteration and evidence for methane generation on the parent bodies of the CM chondrites. Geochim. Cosmochim. Acta 71, 5565-5575 (2007).

30. Nakamura, T., Noguchi, T. \& Yoneda, S. The conditions of aqueous alteration reactions recorded in the Sayama CM2 chondrite. Meteorit. Planet. Sci. 38, A5080 (2003).

31. Ghosh, A., Weidenschilling, S. J., McSween, H. Y. Jr. \& Rubin, A. in Meteorites and the Early Solar System II (eds Lauretta, D. S. \& McSween, H. Y. Jr.) 555-565 (Univ. Arizona Press, 2006).

32. Ludwig, K. R. in Berkeley Geochronology Center Special Publication No. 4, 1-72 (2003)

\section{Acknowledgements}

We thank H. Hiyagon for critical discussions, N. Takahata for technical help with the NanoSIMS analyses, H. Yoshida for technical help with the EPMA analyses, and S. Yoneda and T. Nakamura for providing the Sayama meteorite.

\section{Author contributions}

W.F. and N.S. prepared the polished thin sections of the meteoritic samples and the standard. W.F. performed the NanoSIMS analyses, and collected, processed and refined the data. Y.S. provided technical support for the NanoSIMS analyses. N.S. and K.I. developed the method to synthesise the calcite standard doped with Mn and Cr. W.F. performed the EPMA analyses. H.H. produced the numerical code to calculate the thermal history of the asteroid. W.F. designed the study and prepared the manuscript. All authors discussed the results and commented on the manuscript.

\section{Additional information}

Supplementary Information accompanies this paper at http://www.nature.com/ naturecommunications

Competing financial interests: The authors declare no competing financial interests

Reprints and permission information is available online at http://npg.nature.com/ reprintsandpermissions/

How to cite this article: Fujiya, W. et al. Evidence for the late formation of hydrous asteroids from young meteoritic carbonates. Nat. Commun. 3:627 doi: $10.1038 /$ ncomms 1635 (2012) 